\title{
A Study on the Industrialization Operation of Art Derivatives under the Background of Creative Industries
}

\author{
Rui Kong ${ }^{1}$ and Minghong $\mathrm{Xie}^{2}$ \\ ${ }^{1}$ Tianjin university of commerce, GuangRong Road 409, Beichen District, Tianjin \\ ${ }^{2}$ No.70, Zhongshan District, Taipei City, practice of Creative Industry University doctoral program
}

Keywords: Art market; Art derivatives; Industrialization operation; Creative industry

\begin{abstract}
The so-called art derivative is a community which has the artistic nature and the commodity nature based on the art. Through the museums and other institutions or authorized by artists to develop, so that the product has a certain value of art, become a certain brand value of cultural goods. It plays an important role in people's life, art and market development. So we need to study it, to understand the historical development of art derivatives on the connotation, function analysis, understanding of the industrial operation, and then analyses the industrialization of China's creative industry under the background of art derivatives.

No matter what country, people are going to travel when there is always a relative or friends with some local souvenirs or souvenirs of the habit, for the people is even more so. Before the Chinese people in foreign countries the trend of purchasing more biased in favor of some luxury goods or products of foreign good quality. In addition to the quality of some products that foreign outside, also exposed the contradiction between people abroad in the standard of living rising at the same time with the increasing spiritual and cultural needs, and the purchase of luxury goods is undoubtedly an outlet. In recent years, with the change of wind direction, museums, art galleries and so on have been opened, so that the level of aesthetic appreciation of the Chinese people, shopping also turned to art souvenirs and other art derivatives. Mainly to the working class of the high price of art to create or copy, derivative, etc., to produce pictures, sculptures, decorations, etc., so that ordinary people have the ability to carry out artistic consumption. The art of goods to create a different kind of commercial culture originated in the last century in 50s, Andy Warhol as the representative of the artist making art thoughts and vigorously promote the machine art goods, so as to form an industrial chain, this can be said to be the prototype of art derivatives. Japanese artist Murakami Takashi is also a leading figure in the fashion trend, he has also established a work of art manufacturing factory, in the search for the elite culture and the popular culture of the point. We need to study the market environment and the status of the art shop and art derivatives in China, and the problems in its development are analyzed, in order to determine the final trend of art derivatives is more convenient for the public to accept and still maintain a elite line.
\end{abstract}

\section{The Concept and Category of Art Derivatives}

Art derivatives, which are derived from the role of the arts with goods and the two major value of the arts, is a certain value of Arts. It is the origin of art to the surrounding radiation, so that the arts have more elements and forms, so that art has more meaning and value.

Art derivatives development so far, there are two kinds of good circulation, respectively, with a collection of significance of the print and the art of living supplies. The latter occupy a larger share of the market, with artistic symbols of clothes, furniture, posters and other popular favorite.

\section{The Role of Art Derivatives}

Popularize the Public.The word from the beginning of art seems to be shrouded in a veil of mystery, because of the high cost of making people unable to pay the cost to understand art, but also makes the art circles become a small circle. But art derivatives are different, the nature of the goods it has made its positioning is for the public service, with art derivatives market the development of the art gradually into thousands of households, the art itself is more popular. For the 
public, buy some artistic goods to make themselves appear more artistic, but also has a certain collection and memorial function, sometimes Art Museum, exhibition hall more play tourism attribute; For countries, the popularization of the arts is a good phenomenon, which can make the public more aware of their own culture and art so as to promote the development of art derivatives market industry also added a powerful tax point; For artists, art derivatives has great help to expand its influence, some rare and great works of art can meet the growing cultural and artistic requirements by making art products. In the same, the success of art derivatives has attracted more attention from artists and collectors, which will make the artistic resources more abundant. But art derivatives itself, it is a landmark, marking the art into the public, marking the commercialization of art, public art consumption can be marked, this is the beginning of the era of literary consumption era.

Promote the Transformation and Upgrading of Traditional Industries.Another role in the art of derivatives is to promote the upgrading of traditional manufacturing industries, for the state and enterprises are so. Some less developed countries due to GDP, the level of people's living standards, industrial development and other reasons, making the value of the manufacturing industry is generally not high. This includes our country, while the western developed countries are generally high in this regard, which is also related to the development of the country between the time limit. And the emergence of art derivatives have changed this situation, it can be artists, creative and manufacturing enterprises docking, and make creative ideas are more involved in design, design concept, the product itself, the artistic connotation of the brand effect will greatly enhance. The promotion of these factors is the increase in the value of the product.

Other. For the art world, the emergence of art derivatives is also a good thing, it greatly expanded the scope of art extension, so that the audience has more. Regardless of the artist or art works are not a bad thing, the audience more like the natural and more people are willing to pay for this person is also a lot of. Take Murakami Takashi as an example, its art derivatives price has been as high as $\$ 5000$, but the value of its art works have not been affected, and even rising, for its greatly opened the visibility. For some real love art buyers or collectors, it also gave them a chance to contact with art, now buy art derivatives, the rich might be to buy genuine art, make better development. In different regions of different countries, the equivalent of native art derivatives as existence, this is the one and only refers to its influence, can stimulate the local consumer demand, also can make more people know about the local culture and customs, historical wind speed. From the financial point of view, the prosperity of the art derivatives market provides a lot of tax revenue for the country, providing a large amount of turnover for the Museum of Fine Arts Museum, so that it has more abundant funds.

\section{Art Derivatives Industry in China}

With the growing influence of art derivatives, the formation of its industrial chain is becoming more and more mature, so that it gradually become an influential industry. Art derivatives industry is the first in the development of the western countries, so the current development of the art derivatives industry is also led by western developed countries. The United States and France are the representatives of their industries for the enterprise and the country has brought huge economic benefits, can not be ignored. In our country in Asia, the same is more developed in Japan and South Korea in the forefront of the art derivatives industry, the success of Murakami Takashi's art derivatives is a very typical example. But the development of China's art derivatives industry has a lot of constraints and problems, which is not only a problem of economic conditions, but also the reasons for the arts, markets and so on. The authority of the arts is the art of derivative industry development can not be a last Hom, because the art is different from other products need technical support, it requires the artist to make a license for manufacturing enterprises. But our country in this regard is almost blank, especially as a new industry, in its development has not been concerned about the government and investors, which makes the development of the industry has been further slowed down. For example, most of the current art derivatives in our country originated from the developed countries of the arts and derivatives industry in Japan and South Korea. But the art of 
these products itself is the Chinese people, only by the manufacturers to obtain the authorization of the arts, so as to carry out a design, integration, production of the industrial chain. On the other hand, rampant piracy is one of the factors that affect the development of the art of the derivatives industry, art derivatives investment market is likely to have a large number of similar products in just a few days. To pursue the words and no start, the lack of intellectual property protection for artists and manufacturers, the industry is difficult to develop a healthy. The above authorization and the protection of intellectual property rights can be said that because of the construction of the legal system of our country in the field of art is not perfect, there is no basic system construction, it is difficult to build skyscrapers.

China's art derivatives began to form in the domestic industry when roughly 2006, with the sudden rise of the contemporary art plate and then develop. But in the beginning of the industry, whether it is engaged in R \&amp; D sales of art products or institutions are less, it is difficult to form a real industrial chain. And in the real industrial chain, to make it work properly, in addition to ensure that each link of the industrial operation, the link between the various links is also very important. The connection between China's art derivatives industry chain is not close. The first is the contradiction between the convergence of the artist and production, although more and more artists and industrial manufacturers to cooperate. But this does not mean that the cooperation between the two can be carried out smoothly, many artists do not meet the needs of the design of the market. Perhaps the artist's design is very aesthetic and artistic, but as long as it does not meet the requirements of the market, it is not able to make products to the market. Because art derivatives have the attributes of goods, cannot create the value of art derivatives cannot be called goods, and some of the artist's design is in line with the requirements of the art of the people. But in the use of materials on the restrictions, so that the situation cannot be listed; Second, the sale of art derivatives is difficult to form a larger scale, that is, now the art of derivatives occupies an industry's name without the industry's real name. Art of the sale of the majority of the art area and the Museum of the physical store sales, and some stores provide customized services, but in the final analysis, such sales are still too small, not on the table. According to the survey, China's current art derivatives industry to create value is not high, the highest value of the Imperial Palace museum is a mere 5 million yuan. Foreign well-known museums have annual sales of 500 million yuan or more, the degree of development of Chinese and foreign art derivatives industry from the above we can see a fact. In addition, the development of art derivatives industry in China there are still other problems, such as art derivatives industry chain is too long, the business model and cooperation model is difficult to unity, the degree of specialization manufacturing enterprises is low, but from the consumer perspective. The industry has just started, the audience is already very small, for most people, the art of derivatives is also very strange, these are restricting the development of art derivatives factors. But in the long run, the market of art derivatives industry and its broad, which can be seen only from the total amount of transactions in our country, up to 176 billion 700 million yuan. To develop art derivatives, the author believes that the first to get through the industrial chain, to eliminate the impact of the chain link, and then increase the R \&amp; D and sales of products for the occupation and consolidation of the market to prepare.

\section{Some Suggestions on the Industrialization of Art Derivatives}

Beach Art Exhibition Hall, Art Store. In many places, such as museums, art galleries and other art galleries to visit the end of the line, often there will be an art store, is responsible for selling art museum or Art Museum of art derivatives. Audiences tend to be very happy to buy a few products after the art museum, but because of the consumer's own sake, some people spend more time in the art store than in the art museum. So art stores must be able to harvest a lot of sales, and its sales of products can also make the local culture and arts with the spread of products. The Museum of art plays an indelible role in the art store profit, and profit after art store will benefit to nurture the art museum, the Metropolitan Museum Store is a typical example, the art shop will even open branches abroad. 
To Design Different Products for Consumers. Art derivatives since it is derived from the art of it, so each kind of product will be especially belonging to each type of art store art derivatives all of its behind the Museum of art, and art designers to create derivatives is played in the artist's artistic inspiration. Because the artist's works of art need to be further interpreted so that the general public appreciation and understanding, so that the market will have a market derivatives. And the choice of art shops for the consumption of the crowd is often a number of artists and designers, coupled with the artistic atmosphere of young people and tourists. The former often prefer some books of art, the latter of monumental commodity consumption, consumption ability will choose the cup, book such goods, but the high spending power will choose to print and sculpture goods. Therefore, in the process of the industrialization of art derivatives, it is necessary to take into account the consumer's ability and demand in time, which is the inevitable requirement of the market for art derivatives.

\section{Conclusion}

The art of art derivatives in the form of goods show, let the public can enjoy art, also let the art get a wide range of communication, but also to ease the contradiction between the people's life level and the spiritual and cultural needs. Although the art derivatives industry has developed quite mature, but only for the developed countries, China's art derivatives industry still has a long way to go, there are many problems and suffering in the legal system, industry chain, joint product market etc.. Even so, our country's art derivatives market is very bright, we will overcome all kinds of difficulties, as soon as possible to achieve its industrialization.

\section{References}

[1] Bai Xiao. Analysis of the art market in the operation of the industrialization of art derivatives [J]. public literature and art, 2012,10:284-285.

[2] Wu Donggong. Thinking about culture of art derivatives [J]. Journal of Quanzhou Normal University, 2012,03:98-101.

[3] Cao Liqiu. Art derivatives, the current situation of in-depth investigation of art is also the productivity of the [J]. art market, 2012,19:106-109.

[4] Wang Zhiqin. How far is the industrialization of the industrialization of art derivatives [J]. Chinese new era, 2014,04:60-63.

[5] Li Yunwei. On the characteristics and value of art derivatives [J]. Journal of Zhengzhou University of Light Industry (SOCIAL SCIENCE EDITION), 2015,01:99-104.

[6] Zhang Aihong. Research on the creative development mode of Museum Art derivatives [J]. art, 2015,04:210-214.

[7] Gao Feng. Research on the brand cultivation of art derivatives industry [J]. America and the times (on), 2015,11:14-16.

[8] Li Zhihong. Research on the value characteristics and development strategies of art derivatives [J]. Humanities world, 2016, 05:51-54.

[9] Xi Mu. The development of China's art derivatives industry in the global structure [J]. Journal of Tianjin Academy of Fine Arts, 2015, 06:63-67.

[10] Wang Han. A change from classical art to the mass culture -- a case study of art derivatives [J]. News Herald, 2016,16:11-14. 